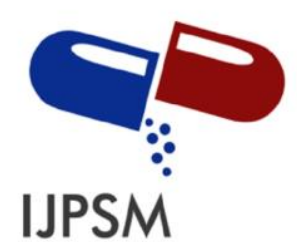

Mawarni Burhan et al, Int. Journal of Pharmaceutical Sciences and Medicine (IJPSM),

Vol.5 Issue. 10, October- 2020, pg. 19-23

ISSN: 2519-9889

Impact Factor: 3.426

\title{
Antioxidant Activities of Genistein: A Review
}

\author{
Mawarni Burhan $^{1}$; Sri Oktavia ${ }^{1^{*}}$; Fitra Fauziah ${ }^{1}$ \\ Department of Pharmacology and Clinical Pharmacy, School of Pharmaceutical Science (STIFARM) Padang, \\ West Sumatra, Indonesia, 25147 \\ *Email: sri.oktavia889@gmail.com \\ DOI: 10.47760/ijpsm.2020.v05i10.001
}

\begin{abstract}
Free radicals are molecules that lose one electron from their lone pair. Free radicals from human cells that take electrons can cause DNA structure changes, resulting in mutations and disease. Substances that can prevent or slow down cell damage caused by free radicals are antioxidants. Many foods, plants, and fruits rich in antioxidants. Genistein is an isoflavonoid class secondary metabolite compound with antioxidant activity that can inhibit the aging process, type 2 antidiabetic, and anti-inflammatory. This review will discuss the activity of genistein as an antioxidant.

Keywords: Antioxidants, free radicals, genistein, isoflavonoid
\end{abstract}

\section{Introduction}

Free radicals are an atom, group, or molecule, which contains one or more unpaired electrons [1]. The biochemical reactions of respiration and metabolism in the reactive oxygen species (ROS) or free radicals are formed [2]. ROS plays a role in physiological processes, such as reducing inflammation, killing bacteria, and regulating blood vessel and organ smooth muscle tone [1]. However, the excessive increase in ROS production in the body can reduce the number of cells, tissues, and the incidence of various diseases [3].

In the neutralization of ROS, the body naturally has defenses, namely endogenous antioxidants such as the enzymes superoxide dismutase (SOD), glutathione peroxidase (GPX), and catalase [4]. Antioxidants work to avoid the damage of cells and tissues, thereby inhibiting the body's oxidative reactions [3]. Several synthetic antioxidant compounds are available, such as butylated hydroxytoluene (BHT), butylated hydroxyanisole (BHA), and tertubutylhydroquinone (TBHQ) [5]. The use of synthetic antioxidants has been reported in several studies to be carcinogenic and may affect organs [5,6]. Therefore, as additional antioxidants, natural antioxidants are more in demand to decrease carcinogenic effects.

Many natural antioxidants are found from phenolic compounds such as the flavonoid group. Flavonoids are a group of secondary metabolites produced by plants [7]. Genistein is one of the most well-known types of isoflavonoids. Genistein [49,5,7-trihydroxyisoflavone or 5,7-dihydroxy-3- (4-hydroxyphenyl) chromen-4-one] (C15H10O5) belongs to the class of natural isoflavonoid flavonoids with a 15-carbon framework, as shown in Figure 1. 


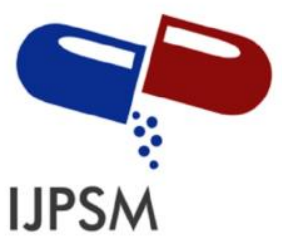

Mawarni Burhan et al, Int. Journal of Pharmaceutical Sciences and Medicine (IJPSM), Vol.5 Issue. 10, October- 2020, pg. 19-23

ISSN: 2519-9889

Impact Factor: 3.426<smiles>O=c1c(-c2ccc(O)cc2)coc2cc(O)cc(O)c12</smiles>

Figure. 1. 2D structure of genistein [8]

Isoflavonoids found in beans, especially soybeans $[9,10,11,12]$. Genistein is also found in several other plants, which are excellent sources of phytoestrogens such as Lupine (Lupinus spp.), Fava beans (Vicia faba), Psoralea (Psoralea corylifolia), and Kudzu (Pueraria lobata) [13]. The genistein content of various fruits, nuts, and vegetables can vary widely [14]. Like other plant constituents, such as lignans, which have an estrogenic effect, genistein is a typical example of a phytoestrogen compound. This plant was first isolated from Genista tinctoria L. in 1899 [11].

According to the American Dietetic Association (ADA), consuming soybeans can neutralize toxins and maintain a healthy body. Genistein acts as a preventive and therapeutic effect for cancer, postmenopausal syndrome, osteoporosis, and cardiovascular disease. Genistein is believed to have an inhibitory effect on red blood cell hemolysis, with dialuric acid or hydrogen peroxide acting as an antioxidant [9]. As time progresses, natural antioxidants' potential can develop into supplements or beauty products, especially in the drug industry. This review article aims to provide information about genistein's potential as an antioxidant.

\section{Methods}

In compiling this review article, the technique used was the literature study method. Also, in making this review article, several keywords, such as "Antioxidants," "Free Radicals," "Genistein," "Isoflavonoids," were used to conduct online research. Research for the main references used in this review article conducted was through trusted websites such as ScienceDirect, NCBI, Researchgate, Google Scholar, and other trusted journals.

\section{Genistein as Antioxidant}

Antioxidants are molecules that can prevent or slow down the oxidation of macromolecules. Antioxidants' role is to reduce or stop this chain reaction by eliminating free radicals or inhibiting other oxidation reactions by oxidizing themselves. Thus, antioxidants are often reducing agents [15]. Various antioxidants are currently found in food, namely, natural antioxidants, synthetic antioxidants, dietary antioxidants, and endogenous antioxidants that play an important role in food preservation [16].

Antioxidants are very important for the health of the body, one of which is anti-aging. The aging process is a natural process that happens from time to time. Both physical and physiological changes can identify the aging process. Physical changes can be characterized by wrinkles, reduced skin elasticity, uneven pigmentation, brown spots, weakness, and a rough appearance. It can be caused by free radicals, which can also accelerate the aging process. The formation of ROS can cause oxidative damage and tissue damage in the skin and cause loss of elasticity in the skin [18]. Genistein reported having acted as an antioxidant, which had a reduction activity value of $\mathrm{IC}_{50}$, using the 2,2'-azinobis-3-ethylbenzo-thiazoline-6sulfonic acid (ABTS) method, which was around $43.17 \mu \mathrm{g} / \mathrm{mL}[17]$. 


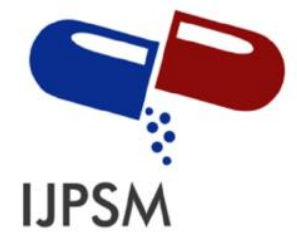

\section{Mawarni Burhan et al, Int. Journal of Pharmaceutical Sciences and Medicine (IJPSM), Vol.5 Issue. 10, October- 2020, pg. 19-23}

Research by Savoia et al. reported that estrogens and phytoestrogens are promising alternatives to the treatment of the aging process through mechanisms associated with estrogen receptors (ER), guanine nucleotide-binding protein (GPER30) coupled receptors, mitochondrial function, and release of nitric oxide (NO). Research showed that genistein is a phytoestrogen that can prevent the aging process due to its antioxidant activity. Genistein can decrease the activation/expression of eNOS and iNOS induced by hydrogen peroxide-induced peroxidative stimulation [19]. In addition to its antioxidant properties and estrogenic/antiestrogenic activity, genistein has several molecular roles, including inhibition of protein tyrosine kinase and topoisomerase II and degradation of phosphatidylinositol and proteins involved in multidrug resistance in cancer cells. The various cellular roles of genistein have led to its use as a modulator of cell proliferation, apoptosis, differentiation, and cell cycle development, especially in cancer cells [20].

Often, antioxidants impact the prevention of diabetes. Diabetes refers to a category of metabolic disorders in which blood glucose elevated, either due to inadequate insulin production or because insulin or both do not respond well to the body's cells. Polyuria (frequent urination), becoming constantly thirsty (polydipsia), and hungry (polyphagia) typically encountered in patients with elevated blood sugar[21]. Relatively specific longterm microvascular complications involving the skin, kidneys, and nerves associated with chronic hyperglycemia in diabetes, as well as an elevated risk of cardiovascular disease (CVD) [22].

According to etiology, it is possible to classify diabetes mellitus; type 1 diabetes and type 2 diabetes are the most common types. Autoimmunity in pancreatic beta cells in the root of type 1 diabetes, in which pancreas beta cells do not produce insulin so that glucose can not reach the cells in the blood. Type 2 diabetes, meanwhile, is a heterogeneous group of disorders characterized by insulin resistance, impaired secretion of insulin, and increased production of glucose in the liver. Type 2 diabetes is a type of diabetes that enough in all individuals worldwide [23]. Uncontrolled ROS can increase oxidative stress to lead to cell injury and cytotoxicity and may, therefore, destroy DNA, proteins, and lipids [24]. The increased development of reactive oxygen (ROS), lipid peroxidation, and antioxidant defenses are related to the increase of diabetes [25].

Genistein in soybeans can increase insulin in plasma and decrease HbAlc in vivo [26]. Amanat et al., 2017 reported that genistein is shown to influence insulin action and increase glucose uptake by promoting glucose transporter translocation on phosphatidylinositol 3-kinase from the rapamycin and protein kinase $\mathrm{C}$ pathways [27]. Genistein controls insulin secretion via two cell lines, INS-1 and MIN6 insulin, through a signal cascade for cAMP activation. Genistein can increase CAMP intracellular and stimulate adenylate-cyclase activation of protein tyrosine kinase (PTK). Glucose-related pathways, such as tyrosine phosphorylation, changes in insulinreceptor counts, disrupted glucose transportation, and intracellular phosphorylation[28]. Besides, the alphaglucosidase enzyme can be inhibited by the genistein [29]. Hyperglycemia can decrease by inhibiting the alpha-glucosidase enzyme's effect when the amount of monosaccharides that can be consumed by the gut is reduced[30].

A study by Jin et al., 2019, reported that genistein reduced inflammation [31]. NF- $\kappa \beta$ act as signals of inflammation and some research suggests that this pathway can enable high lipid, TNF- $\alpha$, endotoxin, and TLR4 associated with inflammation [32]. According to Yin et al., 2019, it concluded that genistein reduces lipid metabolism and TNF- $\alpha$ and can inhibit the expression of TLR4 and mRNA proteins in inflammatory liver cells by decreasing the level of endotoxins in the blood, thereby preventing synthesis in the liver [33].

\section{Conclusion}

Genistein is a secondary metabolite compound of several advantages, one of which is antioxidant. Antioxidants are an effective system for fighting different diseases. Based on this review article, genistein is suspected to be a natural antioxidant capable of resisting aging, antidiabetic and anti-inflammatory processes. 


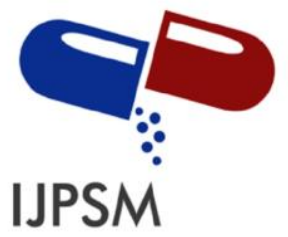
Mawarni Burhan et al, Int. Journal of Pharmaceutical Sciences and Medicine (IJPSM),
Vol.5 Issue. 10, October- 2020, pg. 19-23

ISSN: 2519-9889

Impact Factor: 3.426

\section{References}

[1] Euis R.Y., 2018, Introduction to Free Radicals and Antioxidants. Yogyakarta: Depublish.

[2] Cui H, Kong Y, and Zhang H., 2012, "Oxidative Stress, Mitochondrial Dysfunction, and Aging," J. Signal Transduct., vol. 2012, pp. 1-13

[3] Sen B.D.S., Chakraborty R, Sridhar C, Reddy Y.S.R., 2010, "Free Radicals, Antioxidants, Diseases, And Phytomedicines: Current Status And Future Prospects," Int. J. Pharm. Sci. Rev. Res., vol. 3, no. 1, pp. 91-100

[4] Sanmugapriya E and Venkataraman S., 2006, "Studies on hepatoprotective and antioxidant actions of Strychnos potatorum Linn. seeds on CCl4-induced acute hepatic injury in experimental rats," J. Ethnopharmacol., vol. 105, no. 1-2, pp. 154-160

[5] Li Z.J, Yang F.J, Yang L, and Zu YG, 2018, "Comparison of the antioxidant effects of carnosic acid and synthetic antioxidants on tara seed oil," Chem. Cent. J., vol. 12, no. 1, pp. 1-6

[6] Chen X, Zhang Y, Zu Y, Yang L, Lu Q, and Wang W., 2014, "Antioxidant effects of rosemary extract on sunflower oil compared with synthetic antioxidants," Int. J. Food Sci. Technol., vol. 49, no. 2, pp. 385-391

[7] Gonzales G.B, Smagghe G, Grootaert C, Zotti M, Raes K, and Camp JV, 2015, "Flavonoid interactions during digestion, absorption, distribution, and metabolism: A sequential structure-activity / property relationship-based approach in the study of bioavailability and bioactivity," Drug Metab. Rev., vol. 47, no. 2, pp. 175-190

[8] "https://pubchem.ncbi.nlm.nih.gov/compound/Genistein\#section=2D-Structure.".

[9] Mazumder MAR and Hongsprabhas P., 2016, "Genistein as an antioxidant and antibrowning agents in vivo and in vitro: A review," Biomed. Pharmacother., vol. 82, pp. 379-392

[10] Brodowska K.M., 2017, "Natural flavonoids: classification, potential role, and application of flavonoid analogs," Eur. J. Biol. Res., vol. 7, no. 2, pp. 108-123

[11] Spagnuolo C., 2015, "Genistein and Cancer: Current Status, Challenges," Adv. Nutr., vol. 6, pp. 408-19

[12] Křížová L, Dadáková K, Kašparovská J, and Kašparovský T., 2019, "Isoflavones," Molecules, vol. 24, no. 6

[13] Behloul N and Wu G., 2013, "Genistein: A promising therapeutic agent for obesity and diabetes treatment," Eur. J. Pharmacol., vol. 698, no. 1-3, pp. 31-38

[14] Jaiswal N, Akhtar J, Singh S.P, and Ahsan F., 2019, "An Overview on Genistein and its Various Formulations," Drug Res. (Stuttg)., vol. 69, no. 6, pp. 305-313

[15] Always A, Elsayed A.S.I, Azab A.E, and Quwaydir Q, 2019, "Oxidative stress and antioxidant mechanisms in human body Toxicological effects of Propoxur View project Anti-dyslipidemic and Antiatherogenic Effects of Some Natural Products View project," Artic. J. Biotechnol., vol. 6, no. I-2019, pp. 43-47

[16] Anuj Y, Rewa K, AshwaniY, Seweta S, and Shashi P., 2016, "Antioxidants and its functions in human body," Res. Environ. Life Sci., vol. 9, no. 11, pp. 1328-1331

[17] Geeta, 2019, "Comparison of Antioxidant and Anti-collagenase Activity of Genistein and Epicatechin," Pharm. Sci. Res., vol. 6, no. 2, pp. 111-117

[18] McDaniel D, Farris P, and Valacchi G., 2018, "Atmospheric skin aging - Contributors and inhibitors," J. Cosmet. Dermatol., vol. 17, no. 2, pp. 124-137

[19] Savoia P., 20018, "Anti-oxidative effects of $17 \beta$-estradiol and genistein in human skin fibroblasts and keratinocytes," J. Dermatol. Sci., vol. 92, no. 1, pp. 62-77

[20] Jurzak M, Ramos P, and Pilawa B., 2017, "The influence of genistein on free radicals in normal dermal fibroblasts and keloid fibroblasts examined by EPR spectroscopy," Med. Chem. Res., vol. 26, no. 6, pp. 1297-1305

[21] Lal B.S., 2016, "Diabetes: Causes, Symptoms And Treatments Diabetes: Causes, Symptoms And Treatments,"

[22] Goldenberg R and Punthakee Z., 2013, "Definition, Classification, and Diagnosis of Diabetes, Prediabetes and Metabolic Syndrome," Can. J. Diabetes, vol. 37, no. SUPPL.1, pp. 8-11

[23] Jameson JL, Fauci AS, Kasper DL, Hauser SL, and Longo DL., 2018, Harrison's Principles of Internal Medicine, 20th ed. New York: McGraw Hill Education

[24] Togliatto G, Lombardo G, and Brizzi M.F., 2017 "The future challenge of reactive oxygen species (ROS) in hypertension: From bench to bedside," Int. J. Mol. Sci., vol. 18, no. 9

[25] Braxas H, Rafraf M, Hasanabad S.K, and Jafarabadi MA, 2019, "Effectiveness of Genistein Supplementation on Metabolic Factors and Antioxidant Status in Postmenopausal Women With Type 2 Diabetes Mellitus," Can. J. Diabetes, vol. 43, no. 7, pp. 490-497

[26] Gupta S.K., 2015, "Genistein ameliorates cardiac inflammation and oxidative stress in streptozotocin-induced diabetic cardiomyopathy in rats," Mol. Cell. Biochem., vol. 408, no. 1-2, pp. 63-72

[27] Amanat S, Eftekhari M.H, Fararouei M, Lankarani K.B, and Massoumi S.J., 2018, "Genistein supplementation improves insulin resistance and inflammatory state in non-alcoholic fatty liver patients: A randomized, controlled 


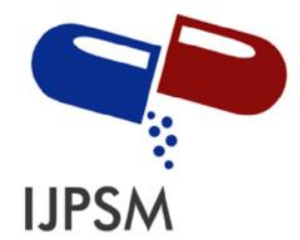

Mawarni Burhan et al, Int. Journal of Pharmaceutical Sciences and Medicine (IJPSM), Vol.5 Issue. 10, October- 2020, pg. 19-23

ISSN: 2519-9889

Impact Factor: 3.426

trial," Clin. Nutr., vol. 37, no. 4, pp. 1210-1215

[28] Ricci E, Cipriani S, Chiaffarino F, Malvezzi M, and Parazzini F., 2010, "Effects of soy isoflavones and genistein on glucose metabolism in perimenopausal and postmenopausal non-Asian women: A meta-analysis of randomized controlled trials," Menopause, vol. 17, no. 5, pp. 1080-1086

[29] Lewicki S., 2018, "Effects of genistein on insulin pathway-related genes in mouse differentiated myoblast C2C12 cell line: Evidence for two independent modes of action," Folia Histochem. Cytobiol., vol. 56, no. 3, pp. 123-132

[30] Febrinda A.E, Astawan M, Wresdiyati T, and Yuliana N.D., 2013. "Antioxidant Capacity and Alpha Glucosidase Inhibitor of Dayak Bulbs Extract," J. Teknol. and Ind. Food, vol. 24, no. 2, pp. 161-167

[31] Cai C, Ma J, Han C, Jin Y, Zhao G, and He X., 2019, "Extraction and antioxidant activity of total triterpenoids in the mycelium of a medicinal fungus, Sanghuangporus sanghuang, " Sci. Rep., vol. 9, no. 1, pp. 1-10

[32] Susutlertpanya W, Werawatganon D, Siriviriyakul P, and Klaikeaw N., 2015, "Genistein Attenuates Nonalcoholic Steatohepatitis and Increases Hepatic PPAR? in a Rat Model,"

[33] Yin Y, Liu H, Zheng Z, Lu R, and Jiang Z., 2019, "Biomedicine \& Pharmacotherapy Genistein can ameliorate hepatic inflammatory reaction in non-alcoholic steatohepatitis rats," Biomed. Pharmacother., vol. 111, no. 74, pp. $1290-1296$ 